\title{
Probabilistic Design and Reliability Analysis of Scour Protections for Offshore Windfarms
}

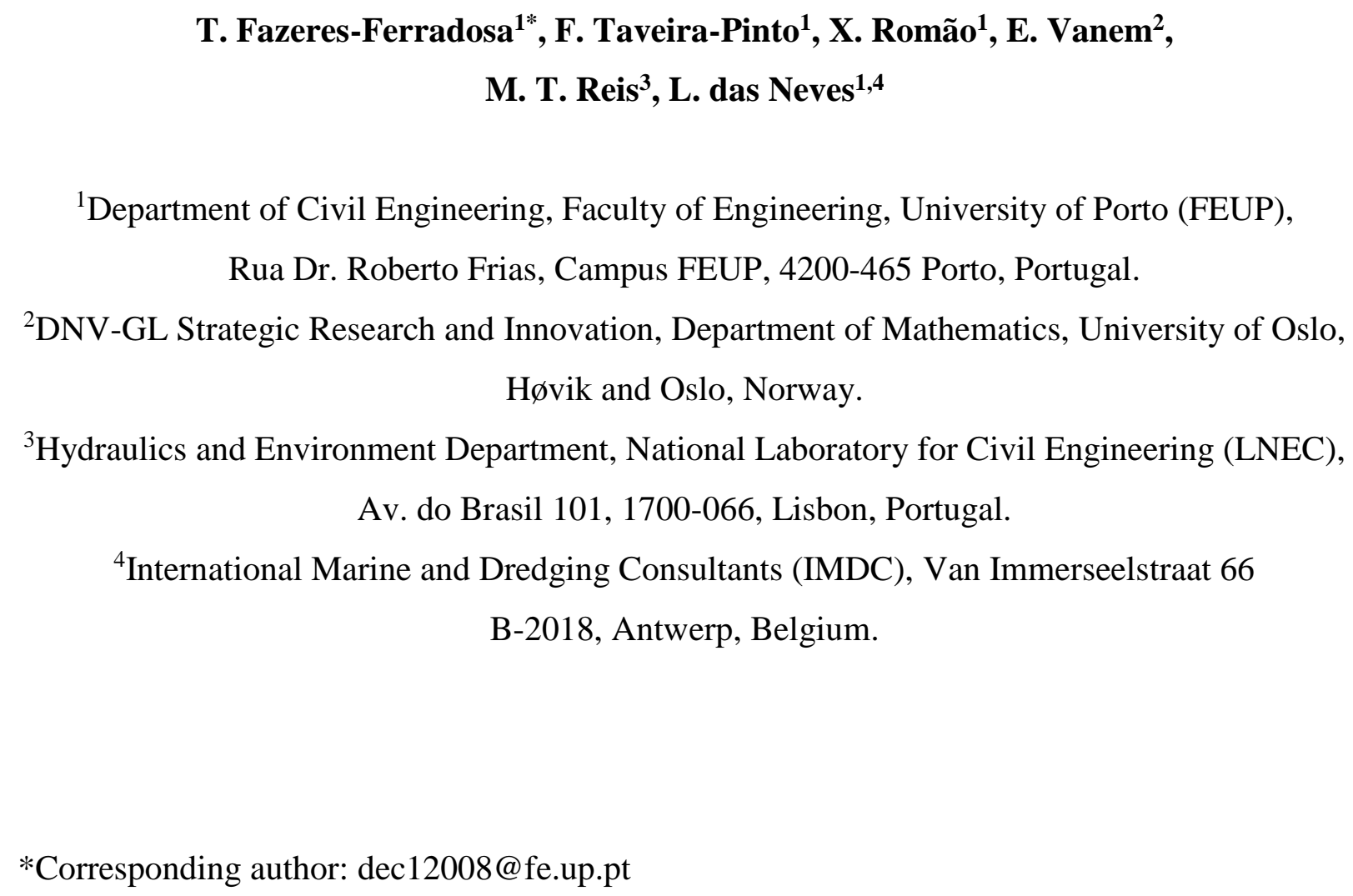


Scour protection is an important component of fixed bottom foundations for offshore wind turbines. Depending on the hydrodynamic conditions, they might be indispensable to avoid the structural collapse of the foundation due to scour phenomena. The design of scour protections is typically deterministic, which often results in overestimated mean diameters of the armour layer. Moreover, the design methodologies currently applied do not provide a measure of safety associated with the proposed design. The present research proposes a novel methodology to assess the safety of the protection and to perform the probabilistic design of static and dynamic scour protections. A case study based on Horns Rev 3 offshore wind farm is used to show how to select the mean stone diameter according to a pre-defined probability of failure of the protection. The results show that a dynamic scour protection could be safely designed with a reduction of the mean stone diameter up to $15 \mathrm{~cm}$, when compared with the statically stable protection.

KEYWORDS: Scour Protection, Probabilistic Design, Offshore Wind Turbines, Optimisation, Reliability, Probability of Failure. 


\section{INTRODUCTION}

The majority of offshore wind turbines with fixed-bottom foundations are based on monopile foundations, i.e. about $81 \%$ of the installed substructures [1]. These fixed foundations are often subjected to scour phenomena, which may lead to structural problems related to loss of moment bearing capacity and fatigue induced instability [2]. Scour phenomena may also lead to significant changes in the natural frequency of the wind turbine. In order to mitigate scour phenomena, one may use a scour protection which typically consists of a filter layer and rock material placed around the monopile to avoid the general loss of sand-bed material [3], as shown in Figure 1.

Figure 1. Scour protection with armour and filter layer

A major aspect of scour protection design is the definition of the mean diameter of the stones $\left(D_{50}\right)$ of the armour layer placed above the filter [4]. Scour protections are typically designed in a deterministic way, mainly based on empirical methodologies that account for the wave and current induced bed shear stress, which may drag the armour stones and eventually, lead to the erosion of the scour protection and the soil around the foundation, e.g. [5], [6] and [7] .

The foundation of an offshore wind turbine roughly corresponds to $30 \%$ of the overall cost (e.g. see [8] or [9]) and an important part of those costs is related to the scour protection. Therefore, several works have been performed aiming at optimising the mean stone diameter, e.g. [10], [11] and [12] tried to improve cost-benefit ratios of the scour protection by means of a reduction in the $\mathrm{D}_{50}$. One of the most recent optimisation methods consists in designing a dynamic scour protection, instead of the static one, commonly used in the industry, e.g. [13] and [14]. 
In static scour protections, the top layer stones are not allowed to move. This means that the mean diameter of the stones is defined so that, for a specific weight of the rock material, the wave- and current-induced shear stress in the foundation's vicinity is not enough to overcome the critical shear stress of the stones [6]. The critical shear stress defines the threshold of motion, i.e. the minimum shear stress necessary to drag the stones from their initial position [5]. In this sense, the failure of a static scour protection is considered to occur when there is movement of the armour stones.

Alternatively, dynamic scour protections allow for a certain degree of movement of the armour stones, without exceeding a maximum exposed area of the filter layer defined by [10] and [14] as $4 \mathrm{D}_{50}{ }^{2}$. Allowing for some movement of the stones enables one to reduce the mean diameter, because there is no need to ensure that the acting shear stress is not equal or larger than the critical one. Dynamic scour protections were extensively studied in [3], which introduced a design criterion based on the dimensionless damage number $\left(\mathrm{S}_{3 \mathrm{D}}\right)$. The damage number provides a measure of the damage expected to occur in the protection for specific hydrodynamic conditions and the mean diameter used. Moreover, [14] conducted a large series of scour tests, based on a physical model of a monopile foundation at a scale of 1:50 (with Froude similitude) and concluded that dynamic scour protections could be obtained for $\mathrm{S}_{3 \mathrm{D}} \leq 1$. The feasibility of dynamic scour protections was later confirmed by [12] and [15], using a similar physical model that encompassed a larger range of the mean stone diameter.

However, despite the optimisations proposed in the literature, the reliability and failure analysis of static and dynamic scour protections have not been extensively addressed. Performing the failure analysis of scour protections not only enables quantifying the safety level of the protection, but it also enables one to perform a probabilistic design, which may solve the problem of the uncertainty and overestimated mean diameters that come from deterministic methodologies. In this paper, a case study utilizing in met-ocean data from the Horns Rev 3 offshore windfarm is used to perform the reliability assessment of a scour protection designed according to deterministic methodologies. Furthermore, a novel probabilistic design method is proposed for static and dynamic scour protections. The new methodology is based on MonteCarlo simulations combined with the failure criteria proposed in [6] and [14], and provides the mean stone diameter of the scour protection for a pre-defined probability of failure.

This paper is a contribution to the very few existent studies concerning the maritime environment and the failure of the protection itself, e.g. [11]. Hence, this paper aims to 
contribute to optimise the design of the protections, under waves and currents combined, by means of failure analysis.

\section{DETERMINISTIC DESIGN AND FAILURE OF SCOUR PROTECTIONS}

The traditional design of scour protections implies the definition of several parameters of the protection, e.g. the thickness of the filter and the armour layer, the extent of the protection and mean diameter of the rock material (i.e. $\mathrm{D}_{50}$ ). The present research is focused on the latter, which must be designed to avoid erosion of the armour layer. There are several deterministic methodologies to determine the value of $\mathrm{D}_{50}$, e.g. [16], [17], [18] or [19]. The current paper is focused on the methodologies defined in [20], due to its wide use and simplicity and in [6] and [14], which correspond to optimised design approaches for static and dynamic scour protections, respectively. For further details on the methodologies applied in this paper, one refers to [3].

\subsection{Static scour protections}

As previously stated the design of statically stable scour protections generally involves the assessment of the bed shear stress induced by the combined effect of waves and currents $\left(\tau_{\mathrm{wc}}\right)$. If the protection is intended for static stability, the armour stones are not allowed to move. Hence, the stones placed in the armour layer must be large enough to ensure that their critical shear-stress $\left(\tau_{\mathrm{cr}}\right)$ is higher than the bed shear stress acting on the protection [21], including the effect of the monopile's presence [20].

In order to account for the monopile's presence, the amplification factor $(\alpha)$ is typically employed. The amplification factor is defined as the ratio of the undisturbed bed shear-stress to the increased shear-stress in the presence of a structure, in this case the monopile foundation. The amplification factor may vary depending on the hydrodynamic condition. According to [14], physical model studies show that for waves alone $\alpha$ varies between 2.2 and 2.5, but when the effect of currents is included one commonly uses $\alpha$ equal to 4 . Note, however, that the amplification factor may be larger depending on the case, e.g. [5] and [18] report other situations where $\alpha$ is larger than 4, e.g. for monopiles under waves and current combined. One of the problems of dealing with waves and currents combined lies in obtaining the maximum bed shear stress caused by their simultaneous action $\left(\tau_{\mathrm{wcmax}}\right)$. In current practice, one of the most widely used methodologies used to obtain $\tau_{\mathrm{wcmax}}$, due to its simplicity and accuracy is the one presented by [20], which is also discussed in [22] and adapted to account for non- 
linear effects in [23]. In order to perform the deterministic design of a scour protection according to [20] the critical shear stress can be defined by Eq.1.

$$
\tau_{c r}=g\left(\rho_{s}-\rho_{w}\right) D_{50} \theta_{c r}
$$

where $\mathrm{g}$ is the gravitational acceleration, $\rho_{\mathrm{w}}$ is the water density, $\rho_{\mathrm{s}}$ is the density of the rock material and $\theta_{\text {cr }}$ is the non-dimensional critical Shields parameter as introduced in [21]. As showed in [6] for sufficiently large non-cohesive sediments, one can use $\theta_{\mathrm{cr}}=0.056$. Then the maximum shear stress, under waves and currents combined, can be assessed according to Eq. 2, where $\tau_{\mathrm{m}}$ is the mean combined bed shear-stress (Eq. 3), $\tau_{\mathrm{w}}$ is the wave-induced bed shear stress, $\tau_{\mathrm{c}}$ is the current-induced bed shear-stress and $\phi$ is the angle between waves and currents [20]:

$$
\tau_{w c \max }=\left[\left(\tau_{m}+\tau_{w} \cos \phi\right)^{2}+\left(\tau_{w} \sin \phi\right)^{2}\right]^{1 / 2}
$$

$$
\tau_{m}=\tau_{c}\left[1+1.2\left(\frac{\tau_{w}}{\tau_{c}+\tau_{w}}\right)^{3.2}\right]
$$

The design value of $\mathrm{D}_{50}$ is the minimum value that complies with Eq. 4, which depends on the selected amplification factor $(\alpha)$.

$$
\tau_{c r}>\alpha \times \tau_{w c \max }
$$

In a similar way, an optimisation for statically stable scour protections was proposed by [6], which introduces an alternative formula (Eq. 5) for $\tau_{\text {wcmax }}$ and a modification of Eq. 1 for the critical shear stress. According to the deterministic design implemented in [6], the critical shear-stress is computed for $\theta_{\text {cr }}$ equal to 0.035 and using a stone diameter for which $67.5 \%$ of the stones (by weight) are retained in the sieving process $\left(D_{67.5}\right)$. These changes are made to account for the fact that stones in a scour protection with smaller grading tend to move faster than those in a scour protection with a wide grading [6]. The maximum bed shear stress, in this case, is obtained from Eq. 5. The mean stone diameter $\mathrm{D}_{50}$ is related with $\mathrm{D}_{67.5}$ by means of Eq. 6 , where $\mathrm{D}_{85}$ and $\mathrm{D}_{15}$ are defined in the same way as $\mathrm{D}_{50}$ and $\mathrm{D}_{67.5}$ for the $15 \%$ and the $85 \%$ 
percentiles. Then the minimum value of $\mathrm{D}_{50}$ is the one that complies with Eq. 7, noting that $\mathrm{D}_{50}$ depends on $D_{67.5}$, which is included in Eq. 1. Moreover, it must be noted that the wave- $\left(\tau_{\mathrm{w}}\right)$ and current-induced bed shear stresses $\left(\tau_{c}\right)$ are dependent on the diameter $\mathrm{D}_{50}$, which is used to calculate the bed roughness $\left(\mathrm{k}_{\mathrm{s}}\right)$, assumed as $2.5 \mathrm{D}_{50}$ in the absence of ripples formation [14]. In the methodology presented by [6] no amplification factor is employed. Research showed that the design proposed by [6] led to smaller stone sizes when compared with the one proposed by [20]. In Eq. 5, 6 and 7, the bed shear stresses are expressed in $\mathrm{N} / \mathrm{m}^{2}$.

$$
\tau_{w c \max }=83+3.569 \times \tau_{c}+0.765 \times \tau_{w}
$$

$$
\log \left(\frac{D_{67.5}}{D_{50}}\right)=0.25 \log \left(\frac{D_{85}}{D_{15}}\right)
$$

4

$$
\tau_{c r}\left(D_{67.5} ; \theta_{c r}=0.035\right)>\tau_{w c \max }
$$

\subsection{Dynamic scour protections}

In order to reduce even more the stone size required for scour protections in marine environment, innovative works have been performed aiming at dynamic scour protections, which allow the armour stones to move. The concept was primarily studied in [13] and later developed and extended by [3], [14] and [15]. The design methodology presented by [14] is still deterministic and mainly based on the definition of the damage number of the protection $\left(\mathrm{S}_{3 \mathrm{D}}\right)$. The damage number corresponds to a non-dimensional measure of the volume eroded per subzone of the scour protection defined as in [14].

The research performed by [14] presented an extensive set of 85 scour tests, including a physical model study at a Froude scale 1/50. This study proposed a formula (Eq. 8) to provide the predicted damage number $\left(\mathrm{S}_{3 \text { Dpred }}\right)$,

$$
\frac{S_{3 \text { Dpred }}}{N^{\text {b0 }}}=a_{0} \frac{U_{m}^{3} T_{m-1,0}^{2}}{\sqrt{g d}(s-1)^{\frac{3}{2}} D_{n 50}^{2}}+a_{1}\left(a_{2}+a_{3} \frac{\left(\frac{U_{c}}{w_{s}}\right)^{2}\left(U_{c}+a_{4} U_{m}\right)^{2} \sqrt{d}}{g D_{n 50}^{\frac{3}{2}}}\right)
$$


where $\mathrm{N}$ is the number of waves in a storm, $\mathrm{U}_{\mathrm{c}}$ is the average current velocity, $\mathrm{s}$ is the ratio between sediment's density $\left(\rho_{\mathrm{s}}\right)$ and water density $\left(\rho_{\mathrm{w}}\right)$, g is the gravitational acceleration, $\mathrm{d}$ is the water depth, $U_{m}$ is the orbital bottom velocity and $\mathrm{w}_{\mathrm{s}}$ is the sediments' fall velocity. $\mathrm{T}_{\mathrm{m}-1,0}$ is the energy spectral wave period, which for a JONSWAP spectrum, with $\gamma=3.3$ can be obtained

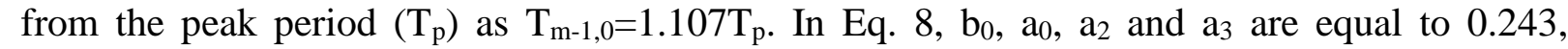
0.00076, -0.022 and 0.0079, respectively. The constants $a_{1}$ (Eq. 9) and a4 (Eq. 10) depend on the existence of following or opposed current $(\mathrm{C})$ to waves $(\mathrm{W})$. $\mathrm{U}_{\mathrm{r}}$ stands for the Ursell number. $\mathrm{D}_{\mathrm{n} 50}$ is the nominal value of the mean stone diameter equal to $0.84 \mathrm{D}_{50}$. Regarding the number of waves in a storm, a value of 3000 waves was assumed. This was identified in [14] and [15] as the number of waves for which the damage number stabilises. However, the authors recognise that the minimum $\mathrm{N}$ for the $\mathrm{S}_{3 \mathrm{D}}$ to stabilise is yet to be fully understood, e.g. [24] performed physical model studies of wide-graded scour protections, concluding that damage still increased after 9000 waves. However, the damage increase reported in [24], for single layer wide-graded scour protections, might not be directly comparable to the type of damage in a scour protection with filter and armour layer tested in [14]. Regarding the latter, [12] noted that the rate of damage development is typically larger in the first 1000 waves and that between 3000 and 5000 waves the damage development significantly decreases.

$$
a_{1}=\left\{\begin{array}{c}
0 \text { for } \frac{U_{c}}{\sqrt{g D_{n 50}}}<0.92 \text { and } W \text { following } C \\
1 \text { for } \frac{U_{c}}{\sqrt{g D_{n 50}}} \geq 0.92 \text { or } W \text { opposed } C
\end{array}\right.
$$

$$
a_{4}=\left\{\begin{array}{l}
1 \text { for } W \text { following } C \\
\frac{U_{r}}{6.4} \quad \text { for } W \text { opposed } C
\end{array}\right.
$$

Eq. 8 provided close estimates of the actual damage number (S3Dmeas) measured in the physical model. The reader is referred to [12], [14] and [15] for details on the physical model and the assessment of the measured damage number.

In [14] it was found that for $\mathrm{S}_{3 \mathrm{D}}$ between 0.25 and 1 there was movement of the armour layer stones without failure, i.e. dynamic stability was achieved. For $\mathrm{S}_{3 \mathrm{D}}$ below 0.25 , no movements 
occurred (statically stable scour protection). It was also reported that dynamic scour protections were obtained for $\mathrm{S}_{3 \mathrm{D}}>1$ (also see [12] and [15]). However, a transition zone was identified for $\mathrm{S}_{3 \mathrm{D}}>1$ in which dynamic profiles were developed in some cases and failure occurred in others. Therefore, a conservative limit of $S_{3 D} \leq 1$ was proposed for the successful design of dynamic scour protections. The majority of the tests performed by [14] were done with a geotextile filter layer. However, in [12] it was found that dynamic scour protections based on the earlier study could be obtained when designing with a granular filter layer. One should note that the proposed limits for the damage number might not be applicable to wide-graded single layer scour protections, since such configuration was not tested in the original data [14] that led to the damage number formula, Eq. 8. Further research should be performed to address the damage behaviour on such type of protections, which are not addressed in the present research. According to the proposed design, the mean diameter of the armour stones is the one that complies with Eq. 11.

$$
\left[a_{0} \frac{U_{m}^{3} T_{m-1,0}^{2}}{\sqrt{g d}(s-1)^{\frac{3}{2}} D_{n 50}^{2}}+a_{1}\left(a_{2}+a_{3} \frac{\left(\frac{U_{c}}{w_{s}}\right)^{2}\left(U_{c}+a_{4} U_{m}\right)^{2} \sqrt{d}}{g D_{n 50}^{\frac{3}{2}}}\right)\right] N^{b_{0}} \leq 1
$$

\subsection{Brief note about the deterministic design of scour protections}

There are several random variables included in the deterministic design of both static and dynamic scour protections. When calculating the bed shear-stress for static protections or the damage number for dynamic ones, it is crucial to define the values of the design wave height $\left(\mathrm{H}_{\mathrm{d}}\right)$ and the associated wave period $(\mathrm{T})$, which are used to determine the orbital bottom velocity $\left(\mathrm{U}_{\mathrm{m}}\right)$. Moreover, the design current velocity $\left(\mathrm{U}_{\mathrm{c}}\right)$ should also be addressed, among several other variables. The deterministic design of scour protections often uses the wave height associated to a specific return period $\left(\mathrm{T}_{\mathrm{r}}\right)$, usually 50 years [6]. In the methodology used for static scour protections, [6] the authors calculate $\mathrm{U}_{\mathrm{m}}$ for $\mathrm{H}_{1 / 10}$, which refers to the mean wave height of the $10 \%$ highest waves in a sea state, for the location where the protection is going to be implemented. On the other hand, [14] uses the orbital bottom velocity calculated from the wave JONSWAP spectrum, with a peak enhancement factor of 3.3, defined by the $\mathrm{H}_{1 / 3}$ and the peak period $\left(\mathrm{T}_{\mathrm{p}}\right)$. The $\mathrm{H}_{1 / 3}$ is analogous to $\mathrm{H}_{1 / 10}$ but it refers to the $33.3 \%$ percentile. It is also often referred to as the significant wave height $\left(\mathrm{H}_{\mathrm{s}}\right)$. The reader must note that despite $\mathrm{H}_{\mathrm{s}}$ and $\mathrm{H}_{1 / 3}$ are often assumed to be equivalent, they might be slightly different, 
because $\mathrm{H}_{\mathrm{s}}$ is directly obtained from the wave spectrum. In the present research, for the sake of simplicity, one makes no distinction between these parameters, which is in agreement with the procedure adopted in [3] when analysing static and dynamic scour protections. The energy method was used to obtain $\mathrm{H}_{\mathrm{s}}$. However, for further details on the wave spectral parameters the reference [3] is recommended.

Although the wave spectrum corresponds to a probabilistic short-term analysis of the sea state characteristics, it does not represent a long-term probabilistic analysis. Hence, even when using spectral analysis, these methodologies do not account for the long-term evolution of the design wave height. Moreover, they do not include the long-term dependence between the wave heights and the peak periods. Also the correlation between waves and current environment is not taken into account. The present research did not focus on waves and current correlation. However, recent works have been performed concerning this subject, e.g. in [25] a conditional model is proposed to perform the joint model of waves and currents. It is concluded that the joint behaviour of these variables produces differences in hydrodynamic loads estimation. In [26] it is concluded that offshore standards tend to overestimate the ultimate limit state loads, because they do not account for long-term correlation between waves and current environment. The deterministic methodologies presented are also not able to consider the combined variability of the environmental factors and the structural parameters of the protection, e.g. the $\mathrm{D}_{50}$, the uniformity parameter of the sediments, the density of the rock material or the protection's thickness (see [3] for details on the structural parameters). However, in a probabilistic design the simulation procedure enables the combination of different possible values of these random variables. Therefore, a probabilistic design allows for the analysis of the occurrence of failure in multiple loading scenarios combined with different characteristics of the protection. However, it is important to note that such probabilistic analysis should be performed within the limits of applicability of the methodologies used to predict damage occurrence in scour protection [27].

\section{RELIABILITY ANALYSIS AND PROBABILISTIC DESIGN OF SCOUR PROTECTIONS}

As stated before, the deterministic design of scour protections does not provide any probability of failure related to the mean stone diameter used in the armour layer. Therefore, one is not able to know how reliable the protection is, neither if the value of $\mathrm{D}_{50}$ is overestimated, namely when using the methodology proposed by [20]. As a consequence, when innovative design 
methodologies are proposed, as in [6] and [14], however, it is not possible to understand if the smaller size that is obtained complies with an acceptable level of safety when compared with the traditional design.

Probabilistic design and reliability assessment of scour protections is a key parameter in order to safely optimise the scour protection. Considering Eqs. 4, 7 and 11, one is able to define the failure criteria of static and dynamic scour protections according to Eqs. 12 and 13, respectively. These equations are referred to as limit state functions. Note that in Eq. 12, the amplification factor must be used if the maximum bed shear stress is calculated according to [20]. This equation also requires knowledge about the wave height and period, which are used to obtain the orbital bottom velocity that is required to calculate $\tau_{\mathrm{wcmax}}, \tau_{\mathrm{w}}$ and $\tau_{\mathrm{c}}$. Details about this calculation are given in [6].

$$
f\left(\tau_{c r} ; \tau_{w} ; \tau_{c}\right)=\tau_{c r}-\tau_{w c \max }
$$

$$
f\left(U_{m} ; U_{c} ; T_{m-1,0} ; D_{50} ; \rho_{s} ; \rho_{w} ; d ; g ; w_{s}\right)=1-S_{3 D p r e d}
$$

If the limit state function $f($.$) is lower than zero, then the failure of the scour protection occurs,$ either because the critical shear stress is exceeded or because the damage number of the protection exceeds the acceptable reference value for dynamic stability.

If one has a data record of the variables included in Eqs. 12 and 13, one may establish distributional models for the various variables and the limit state functions for different combinations of those variables can be simulated. The data record may correspond to hindcast or observed field data of wave heights and periods, current velocity, stone sizes, water depth or other variables. In practical situations, it is sometimes difficult to have a complete record of all variables. This is particularly evident for offshore locations and met-ocean data [28]. This often forces the designer to consider some of those variables as deterministic ones, e.g. $\rho_{\mathrm{w}}$ or $\rho_{\mathrm{s}}$, while the most important ones are analysed from a statistical point of view, e.g. $H_{d}, T_{p}, U_{m}$ or $\mathrm{U}_{\mathrm{c}}$.

The reliability of the scour protection can be quantified by determining the probability of failure $\left(\mathrm{P}_{\mathrm{f}}\right)$ of the protection. In the present research one considers this as the probability of the design criterion of the protection not being met. One can use Monte-Carlo simulations to 
generate the random variables and compute the limit state functions. Then, for a large enough number of simulations $(\mathrm{n})$, the probability of failure $\left(\mathrm{P}_{\mathrm{f}}\right)$ is provided according to Eq. 14 .

$P f=\frac{\#\left(f\left(X_{i}\right)<0\right)}{n}=\frac{\sum_{1}^{n} I\left(f\left(X_{i}\right)\right)}{n}$

where $X_{\mathrm{i}}$ is the vector of random variables and $I\left(f\left(X_{i}\right)\right)$ is an indicator function equal to 1 if $f\left(X_{i}\right)<0$ and equal to 0 otherwise. The number of times that $f\left(X_{i}\right)<0$ is denoted by $\# f\left(X_{i}\right)<0$. For details on the minimum number of simulations (n) to obtain the stable value of $\mathrm{P}_{\mathrm{f}}$ the reader is referred to [29].

The results obtained from Eq. 14 provide the probability of failure for a certain mean diameter of the armour stones. Furthermore, one can derive the probability associated to a range of mean diameters, for specific design conditions, and then design the protection in a probabilistic manner by choosing the value of $\mathrm{D}_{50}$ that corresponds to a certain admissible probability of failure. In the following section a case study is addressed for which the deterministic and probabilistic design is performed and discussed.

\section{CASE STUDY: SCOUR PROTECTION AT HORNS REV 3}

The met-ocean conditions at Horns Rev 3 offshore windfarm, fully available in [30], [31] and [32], are used in order to illustrate how the reliability assessment of a scour protection and its probabilistic design can be performed.

This offshore windfarm is under development and located in the Danish sector of the North Sea (Figure 2), 20-35 km north-west of Blåvands Huk and 45-60 km from the city of Esbjerg. This area is relatively shallow and the water depth ranges from $10 \mathrm{~m}$ to $20 \mathrm{~m}$ [30]. The local seabed is dominated by non-cohesive sands [32]. The position for hindcast modelling corresponds to the following coordinates: Latitude of $55.725^{\circ} \mathrm{N}$ and Longitude of $7.750^{\circ} \mathrm{E}$. The available database resulted in a total of 90553 pairs of significant wave height and peak period. This corresponded to an hourly output resolution for the period of 01-01-2003 to 01-05-2013, e.g. 124 months. The water depth at the referred coordinates was considered to be $\mathrm{d}=18 \mathrm{~m}$. 


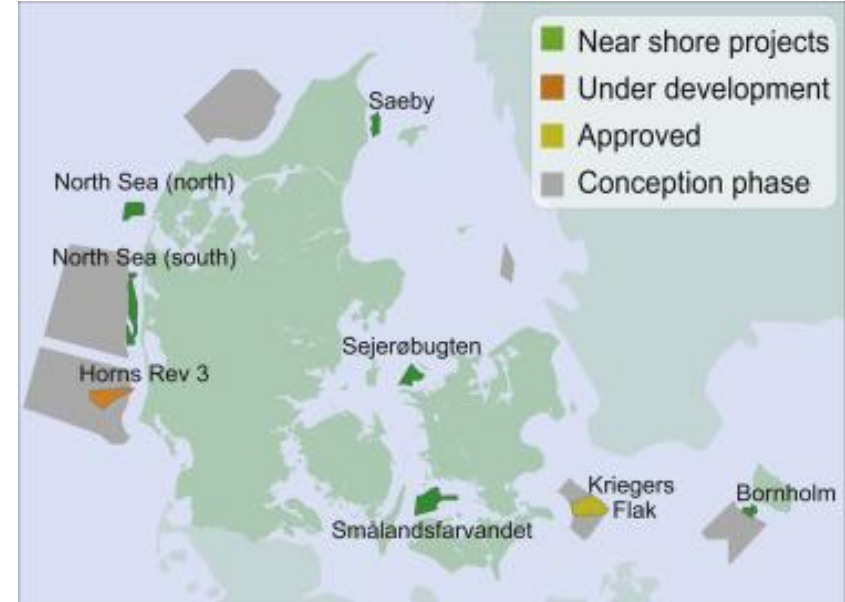

Figure 2. Location of Horns Rev 3 offshore windfarm at the North Sea. [33].

The Conditional model, commonly used in offshore wind turbines design [34] was applied in order to simulate the significant wave height $\left(\mathrm{H}_{\mathrm{s}}=\mathrm{H}_{1 / 3}\right)$ and the peak period $\left(\mathrm{T}_{\mathrm{p}}\right)$, which are further used to compute the variables included in Eqs. 12 and 13, e.g. $U_{m}$ or $T_{m-1,0}$. For details on this model, the reader is referred to [35] or [36]. Regarding the methodology presented in [6] the value of $\mathrm{H}_{\mathrm{d}}=\mathrm{H}_{1 / 10}$ is considered to be equal to $\mathrm{H}_{1 / 10}=1.27 \mathrm{H}_{\mathrm{s}}$, which is valid for the JONSWAP spectrum with a peak enhancement factor of 3.3. The conditional modelling approach is important as it enables one to obtain a model that allows for the variables extrapolation. One only has 10 years and 4 months of data. Thus, being possible that extreme events are not present in the dataset. The use of other models such as the ones based on copulas approach, e.g. [37] or normal transformations, e.g. [38], ultimately influences the probability of failure obtained. It is not the aim of the present paper to address this subject. However, the authors recognise that the analysis of this influence is also a knowledge gap in the literature concerning the reliability of scour protections. A review on possible statistical models for longterm analysis of $\mathrm{H}_{\mathrm{s}}$ and $\mathrm{T}_{\mathrm{p}}$ is given in [39].

Regarding the relative comparison between the probabilities of failure given by each failure criteria, no influence from the actual model is expected since the same generated series are used to simulate the different limit state functions.

The hindcast data concerning $\mathrm{H}_{\mathrm{s}}$ and $\mathrm{T}_{\mathrm{p}}$ is provided in Figure 3, as well as a random sample of 50000 pairs of $\left(\mathrm{H}_{\mathrm{s}} ; \mathrm{T}_{\mathrm{p}}\right)$ obtained from the Conditional Model. A visually good agreement is obtained between the sample and the generated data (Figure 3). The same generated samples of size $\mathrm{n}$ are used to simulate the limit state functions, when determining the probability of failure for the static and dynamic scour protections. It is important to note that when applying the conditional model, some of the generated values may fall outside the original range for which 
the damage number formula, Eq. 8, was derived by [14]. For example, Figure 3 shows that some of the smaller wave heights may present very large peak periods, e.g. 22 to $30 \mathrm{~s}$. However, it is unlikely that such pairs of $\mathrm{H}_{\mathrm{s}}$ and $\mathrm{T}_{\mathrm{p}}$ contribute to damage numbers that exceed $\mathrm{S}_{3 \mathrm{D}}$ equal to 1 . This occurs because, although the peak periods might be overestimated, the significant wave height is not large enough to produce damage numbers above 1 , according to Eq. 8. Nevertheless, the future research should also be focused on the effects of the generation model in the predicted damage numbers given according to [14], i.e. Eq. 8.

The statistical model, used to generate the random values of significant wave height and peak period, will also affect the reliability assessment of the scour protection. For example, if extreme wave heights (or periods) are underestimated, one may underestimate the probability of failure associated to each criterion. Conversely, if the extreme wave heights (or periods) are overestimated, the estimated probabilities of failure might be too conservative when compared to the truthful (and unknown) value. Since the same model is used for all methodologies this does not pose a problem in terms of the criteria comparison. However, it does influence the assessment of each probability per si. Nevertheless, this remains as a problem of the model fitting more than the methodology of reliability assessment discussed in the following sections. Regarding this matter one must also note that the accuracy of the probabilities is also dependent on the quality of the hindcast data, which in this case only has 10 years and 4 months. However, for offshore locations the available data is often scarce and one has to fit the statistical model to the records available, in spite of them being rather short. 


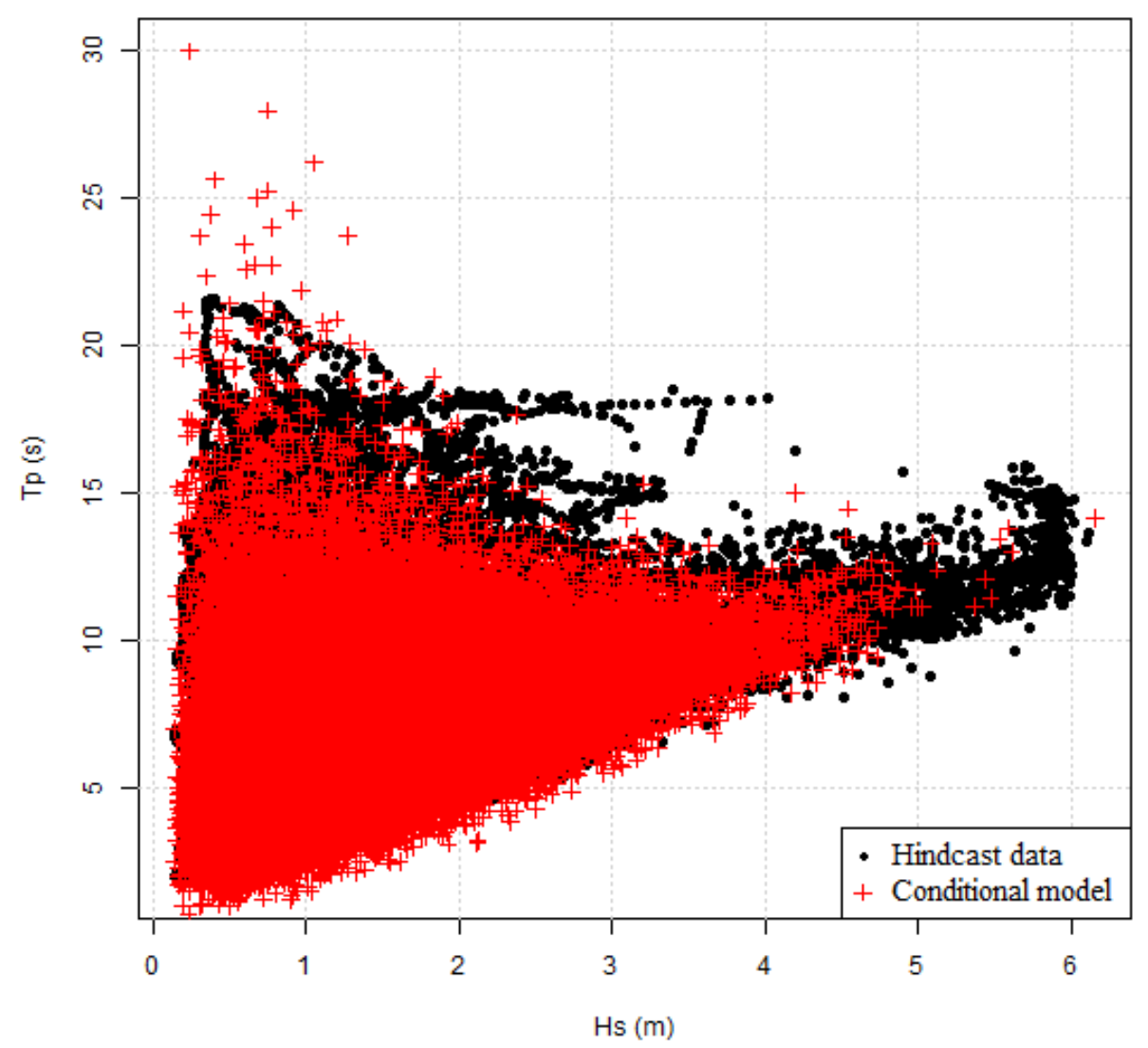

Figure 3. Hindcast data concerning the significant wave height and peak period at Horns Rev 3 and random generated sample with $n=50000$ pairs of $\left(H_{s} ; T_{p}\right)$.

As a model simplification, the current velocity is considered independent from the wave height and the peak period. No time series were available for the current velocity $\left(\mathrm{U}_{c}\right)$. Based on the values reported in [30], this study considered that the current velocity followed a Weibull distribution, with an equivalent mean of $0.4 \mathrm{~m} / \mathrm{s}$ and a standard deviation of $0.2 \mathrm{~m} / \mathrm{s}$. While the methodology presented in [20] considers different angles between $U_{c}$ and the wave's direction, the methodology presented in [14] only considers unidirectional or opposing waves and currents. Therefore, a random angle of $0^{\circ}$ and $180^{\circ}$ was assigned to each simulation of the limit state functions. This is also a simplification of the present model but the authors recognise that improvements can be made if one considers a wider range of this angle. Nevertheless, this must be seen as a limitation of the criteria studied previously, more than a limitation of the reliability assessment proposed here. If concurrent directional wave and current data are available, it is possible to establish a probability distribution for the angle and simulate this accordingly. Note 
The water depth is also an important varying parameter that may influence the damage number and the acting bed shear stress at the armour layer. However, in the present model and as a simplification, this parameter was assumed to be deterministic variable in the process. At the present stage of the research, a preference was given to the accurate model of the significant wave height and the correlated values of the wave peak period. Nevertheless, it must be noted that reductions in the water depth may lead to an increasing severity of the scour process on the armour layer of the scour protection, eventually, contributing to reduce the reliability of a scour protection, with the same thickness and the same mean stone diameter. On the other hand, the water depth decrease may lead to limitations on the non-breaking wave heights at the protection's location. Therefore, if the water depth is reduced one also has to account for the effects on the wave's characteristics, which may difficult the straightforward identification on the immediate effect on the damage number and the combined bed shear stress. To avoid a possible bias on the interpretation of such effects from the water depth and the wave height, the model was simplified to assume a constant water depth.

Horns Rev 3 windfarm is under development at the present date. However, [31] and [40] suggest $\mathrm{D}_{50}=0.4 \mathrm{~m}$ or $0.35 \mathrm{~m}$ as possible mean stone diameters for the protection, respectively. Moreover, in the present case study the following variables are analysed as deterministic, according to the methodologies previously mentioned: the density of the rock material was considered as $\rho s=2650 \mathrm{~kg} / \mathrm{m}^{3}, \mathrm{~N}=3000$ waves, $\rho_{\mathrm{w}}=1025 \mathrm{~kg} / \mathrm{m}^{3}, \mathrm{~g}=9.81 \mathrm{~m} / \mathrm{s}^{2}$. The uniformity parameter $\left(\sigma_{\mathrm{U}}=\mathrm{D}_{85} / \mathrm{D}_{15}\right)$ was defined as 2.5 as in [6]. In the following section the results concerning the deterministic and the probabilistic design are presented and discussed. The simulated values of $H_{s}, T_{p}$ and $U_{c}$ are provided from the conditional model fitted to the hindcast data available for Horns Rev 3, as seen before.

\section{DESIGN RESULTS}

\subsection{Deterministic design of scour protections}

The deterministic design of scour protections typically uses the design wave height as the significant wave height associated to a return period $\left(\mathrm{T}_{\mathrm{r}}\right)$ of 50 years. In [30], the Peak Over Threshold based on the Generalised Pareto distribution determined that, for this location, $\mathrm{H}_{\mathrm{d}}$ was equal to $\mathrm{H}_{\mathrm{s} 50 \mathrm{year}}=6.7 \mathrm{~m}$. The concurrent wave peak period was calculated as for a JONSWAP spectrum with a wave enhacement factor of $\gamma=3.3$, i.e. $T_{p}=4.4\left(\mathrm{H}_{\mathrm{s}}\right)^{0.5}=11.4 \mathrm{~s}$. However, the hindcast data available concerns to 10 years and 4 months only. Therefore, one 
should keep in mind that a considerable uncertainty is inherent to the estimated values for $\mathrm{T}_{\mathrm{r}}=50$ years.

The design performed with [6] uses the mean wave height of the $10 \%$ highest waves in order to calculate the orbital bottom velocity. Thus, $\mathrm{U}_{\mathrm{m}}$ is calculated for $\mathrm{H}_{1 / 10}=1.27 \mathrm{H}_{50 \text { year }}=8.5 \mathrm{~m}$, assuming a JONSWAP spectrum with a peak enhancement factor of 3.3. The methodology [14] was applied with the significant wave height associated to $\mathrm{T}_{\mathrm{r}}=50$ years as in [20]. Both of these methodologies use the peak period associated to the selected $\mathrm{H}_{\mathrm{s}}$. The orbital bottom velocity for [6] is obtained with the linear wave theory, while in [14] is directly obtained from the wave spectrum (also see [3]).

Table 1 provides the results for the deterministic design, which depends on the characteristic values used to calculate the shear stress on the protection. Moreover, for the methodology presented in [20], the mean diameter of the armour stones is calculated for several amplification factors $(\alpha)$. A similar application is shown in [14]. One can see that the values obtained in this case are similar to the ones reported for the referred deterministic design.

Table 1 shows that the innovative methodologies proposed by [6] and [14] lead to smaller diameters when compared with the one obtained by the methodology from [20], which is more conservative. This is a result of the different failure criteria that were selected and of the different design values that were used. It is also possible to confirm that the dynamic scour protection corresponds to the smallest stone size. In dynamic scour protections the difference between the design for opposing waves and currents is not very noticeable, due to the small mean current velocity $\left(U_{c}=0.4 \mathrm{~m} / \mathrm{s}\right)$. For large values of $U_{c}$, say $1-1.5 \mathrm{~m} / \mathrm{s}$, the differences in $\mathrm{D}_{50}$ are larger, as shown in [3]. Nevertheless, the largest stone size given by [14] is associated to waves opposing current. This is consistent with the fact that the damage number tends to be larger for waves opposing currents than for waves following currents, as shown in [3] and [14]. For a typical rip-rap scour protection, commonly placed with fall-pipe vessels [12], the diameters given by the methodology in [20] for an amplification factor of 3 and 4 are rather large. Moreover, the diameters obtained $\left(\mathrm{D}_{50}=1.41 \mathrm{~m}\right.$ and $\left.\mathrm{D}_{50}=2.56 \mathrm{~m}\right)$ are also very large when compared with the size of rock material commonly used. Typical diameters of the armour stones reported in the literature range from $0.15 \mathrm{~m}$ to $0.60 \mathrm{~m}$ depending on the site conditions [7]. Table 1 provides acceptable diameters when compared to existent scour protections for waves and currents combined, e.g. the offshore windfarms of Horns Rev $1\left(\mathrm{H}_{\mathrm{s}}=5.2\right)$ and Egmond aan Zee $\left(\mathrm{H}_{\mathrm{s}}=3.6\right)$ use $\mathrm{D}_{50}=0.40 \mathrm{~m}$. An extensive review of some design examples can be found in [7] and [41]. The designs obtained by the methodologies from [6] and [14] seem 
more appealing since the corresponding diameter of the stones is considerably smaller. Furthermore, the dynamic design of the scour protection enables one to use $\mathrm{D}_{50}=0.26 \mathrm{~m}$, which is less than half of the size obtained by the methodology from [20] with $\alpha=2$.

A question arises from Table 1: "Are the reduced diameters proposed by [6] and [14] as safe as those proposed by [20]?" In order to answer this question, the reliability of the proposed solutions is assessed. One considers that the wave height and the peak period are randomly generated from the Conditional model [35], while the mean current velocity follows the previously mentioned distribution. Random series of these variables were used to simulate the limit state functions, i.e. Eqs. 12 and 13. The probability of failure of each diameter was then calculated according to Eq. 14. The results are summarized in Figure 4 which presents the probability of failure as a function of the number of simulations performed.

Table 1. Deterministic design of the scour protection at Horns Rev 3.

[20]

Static Scour Protection
[6] Static Scour Protection
[14]

Dynamic Scour Protection

\begin{tabular}{|c|c|c|c|c|c|c|c|c|}
\hline$\theta$ & 0.056 & {$[-]$} & $\theta$ & 0.035 & {$[-]$} & Direction & $0 ; 180$ & o \\
\hline$\sigma_{\mathrm{u}}$ & 2.5 & {$[-]$} & $\sigma_{\mathrm{u}}$ & 2.5 & {$[-]$} & $\mathrm{N}$ & 3000 & waves \\
\hline$\rho_{\mathrm{s}}$ & 2650 & {$\left[\mathrm{~kg} / \mathrm{m}^{3}\right]$} & $\rho_{\mathrm{s}}$ & 2650 & {$\left[\mathrm{~kg} / \mathrm{m}^{3}\right]$} & $\rho_{\mathrm{s}}$ & 2650 & {$\left[\mathrm{~kg} / \mathrm{m}^{3}\right]$} \\
\hline$\rho_{\mathrm{w}}$ & 1025 & {$\left[\mathrm{~kg} / \mathrm{m}^{3}\right]$} & $\rho_{\mathrm{w}}$ & 1025 & {$\left[\mathrm{~kg} / \mathrm{m}^{3}\right]$} & $\rho_{\mathrm{w}}$ & 1025 & {$\left[\mathrm{~kg} / \mathrm{m}^{3}\right]$} \\
\hline $\mathrm{d}$ & 18 & $\mathrm{~m}$ & $\mathrm{~d}$ & 18 & $\mathrm{~m}$ & $\mathrm{~d}$ & 18 & $\mathrm{~m}$ \\
\hline$D_{p}$ & 6.5 & $\mathrm{~m}$ & $D_{p}$ & 6.5 & $\mathrm{~m}$ & $D_{p}$ & 6.5 & $\mathrm{~m}$ \\
\hline$\gamma$ & 3.3 & {$[-]$} & $\gamma$ & 3.3 & {$[-]$} & $\gamma$ & 3.3 & {$[-]$} \\
\hline $\mathrm{H}_{\mathrm{s}}$ & 6.7 & $\mathrm{~m}$ & $\mathrm{H}_{\mathrm{s}}$ & 6.7 & $\mathrm{~m}$ & $\mathrm{H}_{\mathrm{s}}$ & 6.7 & $\mathrm{~m}$ \\
\hline $\mathrm{T}_{\mathrm{p}}$ & 11.4 & S & $\mathrm{T}_{\mathrm{p}}$ & 11.4 & $\mathrm{~s}$ & $T_{p}$ & 11.4 & $\mathrm{~s}$ \\
\hline $\mathrm{U}_{\mathrm{c}}$ & 0.4 & $\mathrm{~m} / \mathrm{s}$ & $\mathrm{U}_{\mathrm{c}}$ & 0.4 & $\mathrm{~m} / \mathrm{s}$ & $\mathrm{U}_{\mathrm{c}}$ & 0.4 & $\mathrm{~m} / \mathrm{s}$ \\
\hline $\mathrm{U}_{\mathrm{m}}$ & $\mathrm{U}_{\mathrm{m}}\left(\mathrm{H}_{\mathrm{s}} ; \mathrm{T}_{\mathrm{p}}\right)$ & $\mathrm{m} / \mathrm{s}$ & $\mathrm{U}_{\mathrm{m}}$ & $\mathrm{U}_{\mathrm{m}}\left(\mathrm{H}_{1 / 10} ; \mathrm{T}_{\mathrm{p}}\right)$ & $\mathrm{m} / \mathrm{s}$ & $\mathrm{U}_{\mathrm{m}}\left(\mathrm{H}_{\mathrm{s}} ; \mathrm{T}_{\mathrm{p}}\right)$ & $\mathrm{U}_{\mathrm{m}}\left(\mathrm{H}_{\mathrm{s}} ; \mathrm{T}_{\mathrm{p}}\right)$ & $\mathrm{m} / \mathrm{s}$ \\
\hline $\mathrm{g}$ & 9.81 & $\mathrm{~m} / \mathrm{s}^{2}$ & $\mathrm{~g}$ & 9,81 & $\mathrm{~m} / \mathrm{s}^{2}$ & $\mathrm{~g}$ & 9.81 & $\mathrm{~m} / \mathrm{s}^{2}$ \\
\hline & Result & & & Result & & & Result & \\
\hline $\mathrm{D}_{50}(\alpha=2)$ & 0.610 & \multirow{3}{*}[\mathrm{m}]{} & \multirow{3}{*}{$\mathrm{D}_{50}$} & \multirow{3}{*}{0.540} & \multirow{3}{*}[\mathrm{m}]{} & $\mathrm{D}_{50}\left(0^{\circ}\right)$ & 0.250 & \multirow{3}{*}{ [m] } \\
\hline $\mathrm{D}_{50}(\alpha=3)$ & 1.410 & & & & & & & \\
\hline $\mathrm{D}_{50}(\alpha=4)$ & 2.560 & & & & & $\mathrm{D}_{50}\left(180^{\circ}\right)$ & 0.260 & \\
\hline
\end{tabular}




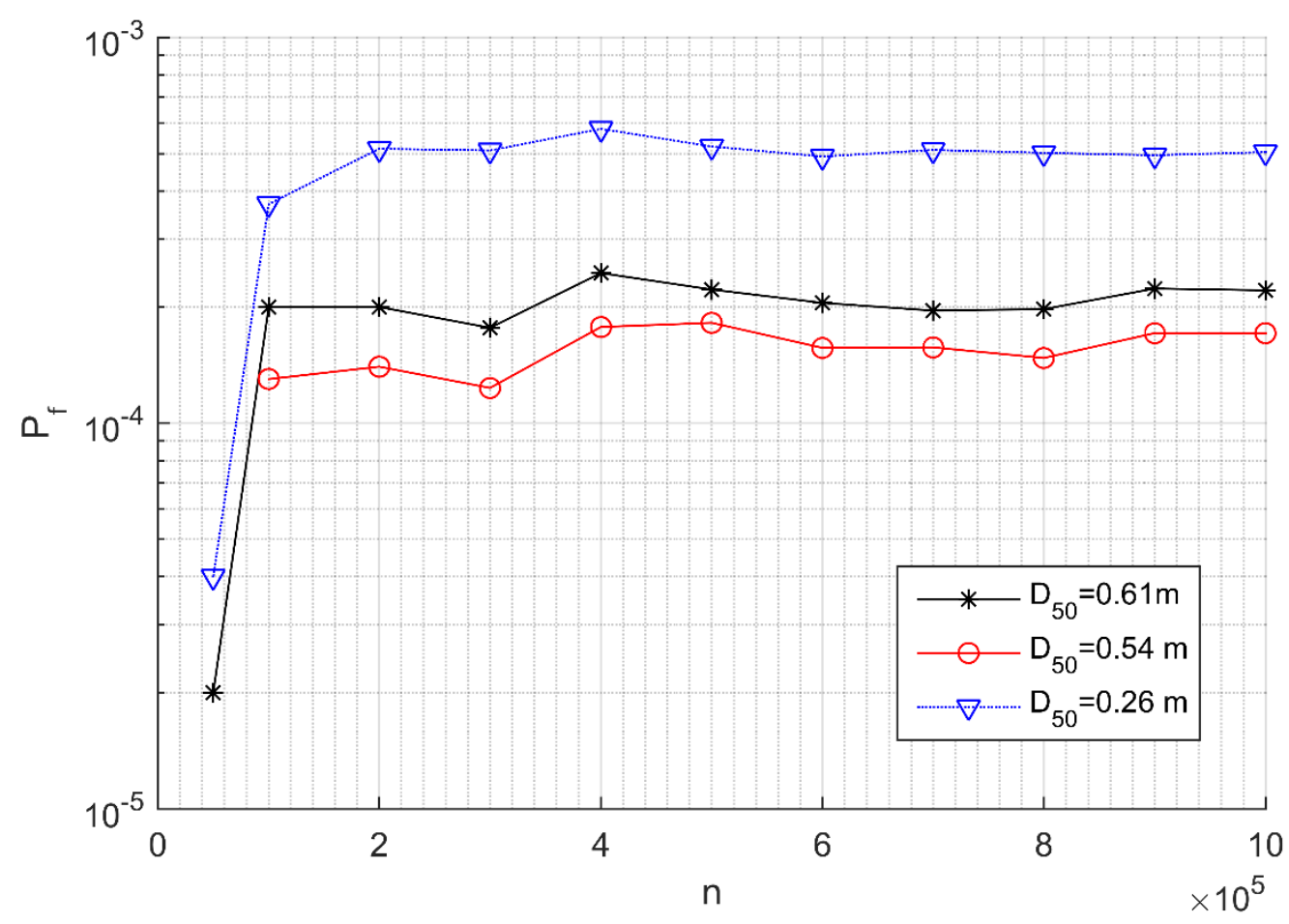

Figure 4. Probability of failure for each design methodology versus number of simulated values of $\mathrm{H}_{\mathrm{s}}, \mathrm{T}_{\mathrm{p}}$ and $\mathrm{U}_{\mathrm{c}}$.

Figure 4 shows that the methodology from [6] leads to the lowest probabilities of failure. The values of the probability seem rather stabilised after $n=300000$. The probabilities are plotted in the logarithmic scale. It is somehow counterintuitive that $\mathrm{D}_{50}=0.54 \mathrm{~m}$ yields a lower probability of failure $\left(\mathrm{P}_{\mathrm{f}}=1.7 \times 10^{-4}\right)$ that $\mathrm{D}_{50}=0.61 \mathrm{~m}\left(\mathrm{P}_{\mathrm{f}}=2.2 \times 10^{-4}\right)$. However, the failure criteria that leads to those probabilities is different and as also noted by [27] the failure criteria does influence the probability of failure. Therefore, the probability of failure must be understood as the chance of a design criterion is not being met, under the random loading conditions given by $H_{s}, T_{p}$ and $\mathrm{U}_{c}$. This means that $\mathrm{D}_{50}=0.54$ has a smaller probability of not meeting the design criterion given by [6], than the $\mathrm{D}_{50}=0.61$ has of not meeting the design criterion given by [20]. Nevertheless, Figure 4 seems to indicate that both methodologies for static design lead to diameters that have very similar probability of failure, i.e. the same probability that each design criterion is not being respected. This suggests that the optimised solution provided by [6] not only gave a smaller $\mathrm{D}_{50}$ than [20], but it seems to be within the same level of safety, i.e. $\mathrm{P}_{\mathrm{f}}$ in the order of $10^{-4}$.

However, the reliability assessment was performed for an amplification factor of 2 . Note that several authors typically employ $\alpha=4$ in several design situations, e.g. [3], [42] or [43], which means that those solutions tend to be more conservative than $\mathrm{D}_{50}=0.61 \mathrm{~m}$. One can argue that 
the curve given by [20] with $\alpha=2$ is not directly comparable to the curve given by [6]. As it will be discussed further, this argument is reasonable due to several differences between the static design criteria.

The probabilities associated to the methodology [14] are slightly larger than those obtained with the statically stable solutions from [6] and [20]. The $\mathrm{D}_{50}=0.26 \mathrm{~m}$ has $\mathrm{P}_{\mathrm{f}}=5 \times 10^{-4}$. However, if one takes into consideration the variability and the uncertainty of the met-ocean environment, the values obtained might be considered acceptable in light of the substantial reduction of the mean stone diameter. An important aspect that can be noted is the consistency in the criteria provided by [6] and [14]. The design of a dynamic scour protection with a reduced diameter $\left(\mathrm{D}_{50}=0.26 \mathrm{~m}\right)$ gives a slightly larger probability of failure $\left(\mathrm{P}_{\mathrm{f}}=5 \times 10^{-4}\right)$ than the static scour protection $\left(\mathrm{P}_{\mathrm{f}}=1.7 \times 10^{-4}\right)$ with a larger mean diameter $\left(\mathrm{D}_{50}=0.54 \mathrm{~m}\right)$. Once again, note that the failure of both protections is analysed under different failure criteria. In the present case, it seems that a dynamic scour protection has a reliability level, which is in the same order as the static one designed according to [14], i.e. both of them in order of $10^{-4}$. This is of great importance, because not only the size reduction may lead to lower costs of the scour protection, but it also minimizes the occurrence of other problems, e.g. the edge scour phenomenon, which increases for large stone diameters due to the sudden increase of the bed-roughness [44].

The results from Table 2 are somehow difficult to compare with other cases in the literature, because there is an evident lack of research performed on the reliability and safety assessment of scour protections analysed by means of the probabilities of failure. A reliability assessment of statically stable scour protections, designed according to [6], is presented by [11]. However, the authors do not consider the correlation effects between the significant wave height and the peak period. Moreover, $H_{p}, T_{p}$ and $U_{c}$ were assumed to follow Gaussian distributions. The minimum probability of failure obtained by [11] was in the range of $10^{-3}$ for a global safety factor of 1.5, defined as the ratio of the acting bed shear stress to the critical shear-stress. These values seem to indicate that the model chosen for the random variables considerably affects the probability of failure. Such evidence was also confirmed in studies related to other offshore components, e.g. in mooring lines by [45].

Table 2. Stabilized probability of failure calculated with the Conditional model model (124 months).

Design Methodology $\quad \mathrm{D}_{50}[\mathrm{~m}] \quad \mathrm{P}_{\mathrm{f}}(\mathrm{n}=1000000)$




\begin{tabular}{lcc}
\hline Static Scour Protection [20] & 0.61 & $2.2 \times 10^{-4}$ \\
\hline Static Scour Protection [6] & 0.54 & $1.7 \times 10^{-4}$ \\
\hline Dynamic Scour Protection [14] & 0.260 & $5 \times 10^{-4}$ \\
\hline
\end{tabular}

The scour protection at a monopile foundation consists of a system designed to mitigate scour related failures. However, if the scour protection fails, the monopile is not expected to fail immediately nor results in loss of human life (offshore wind turbines are unmanned structures). In this sense, one could argue that probabilities of failure in the order of $10^{-4}$ might be acceptable for the scour protection.

The probabilities of failure presented in Table 2 are computed based on a 124 months record. Regarding the probability of failure in scour protections there is no guidance or obligatory offshore standards to be followed, typically, in marine structures the annual probability of failure may range from $10^{-3}$ to $10^{-6}$, depending on the systems redundancy, the warning prior to failure and the possibility of loss of life, e.g. see [46] and [47]. The values obtained for the present design might be difficult to convert to equivalent annual values for a proper comparison with the mentioned references. This is due to the fact that there is a dependence between the sea-state conditions for each simulation, because one is using hourly data. Since the event from hour $\left(t_{i}\right)$ might be dependent from the event of hour $\left(t_{i-1}\right)$, one is not able to assume a constant rate of failure. Thus, the annual probability of failure will not be equal to the number of hours in a year multiplied by the probabilities obtained in Table 2. Of course the time step used to fit the joint model of $\mathrm{H}_{\mathrm{s}}$ and $\mathrm{T}_{\mathrm{p}}$ also leads to an influence in $\mathrm{P}_{\mathrm{f}}$. Regarding the comparative analysis between criteria this does not pose a problem, because the same hourly data is used for the three design situations. However, when trying to analyse the probability of failure associated to extreme values, e.g. $H_{s}$ associated to $T_{r}=100$ years or similar, the values of $P_{f}$ are not directly comparable with the ones being focused in this research.

The effects of the temporal resolution used to compute the probability of failure in offshore engineering applications are analysed in [48]. Although favouring models, which are fitted to annual maxima or clustered data, may lead to a better assessment of the extreme events, it must be recognised that this may also lead to uncertainties when the records are rather short, as this one with only 124 months. Nevertheless and as stated before, the main idea from the comparison presented in Figure 4 and Table 2 is that the deterministic solutions seem to present similar reliability measures. The authors recognise that further research considering other data 
records and other temporal resolutions of $\mathrm{H}_{\mathrm{s}}$ and $\mathrm{T}_{\mathrm{p}}$ should be carried in order to properly compare these probabilities of failure with the annual return period values currently employed in structural design of offshore foundations.

\subsection{Probabilistic design of scour protections}

Instead of solely assessing the probability of failure of the scour protection, it might be relevant to analyse the values of the mean stone diameter associated to a specific probability. This can be performed by determining the relationship between $\mathrm{D}_{50}$ and $\mathrm{P}_{\mathrm{f}}$ according to each methodology.

In Figure 5, this relationship is established for the design of a static scour protection according to the methodologies presented by [6] and by [20], with an amplification factor of 2 applied to the latter. Results are obtained for a number of simulations set to 300000 , which is large enough to ensure a stabilised value of the probability of failure (see Figure 4).

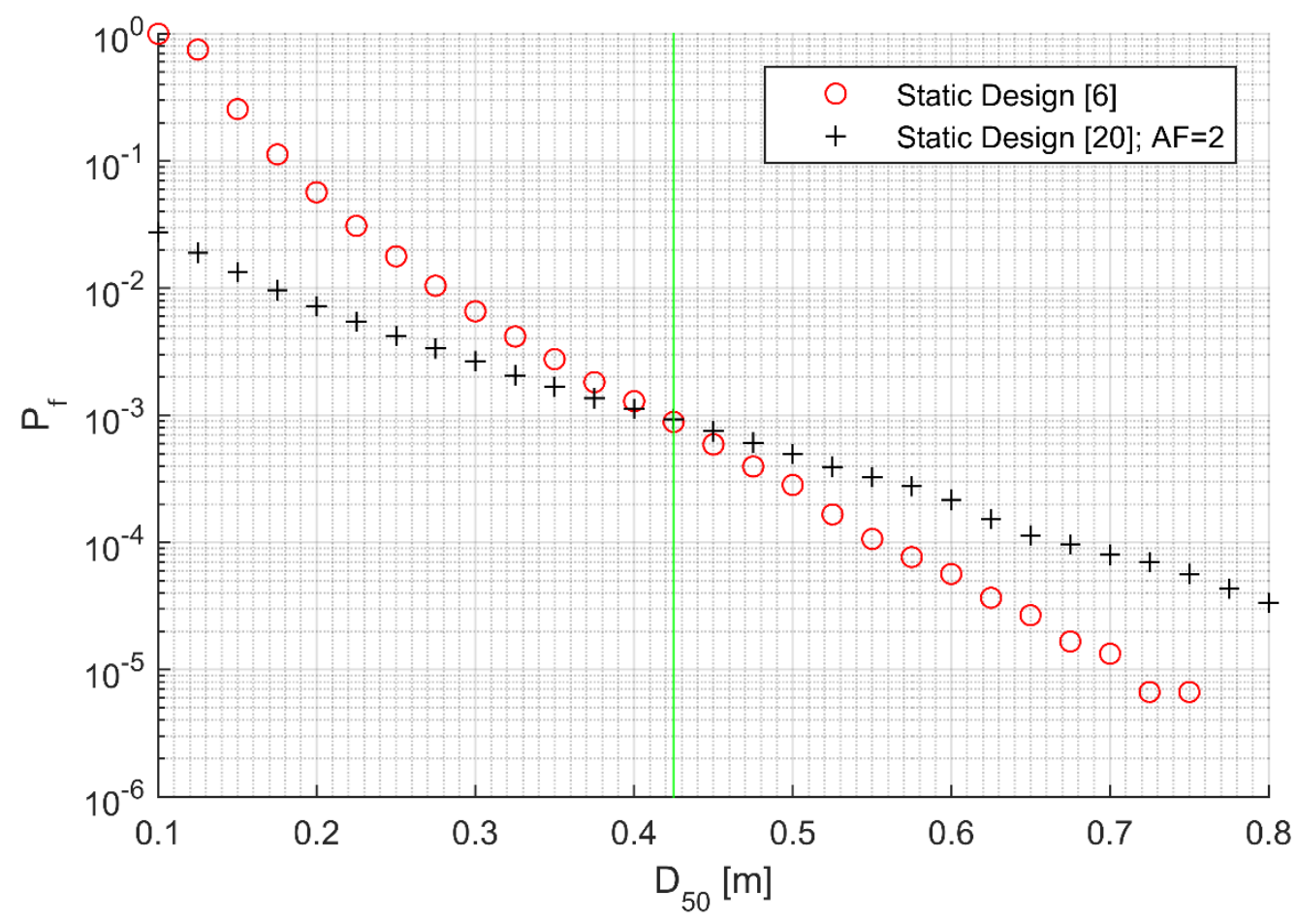

Figure 5. Safety comparison between static design criteria $(n=300000)$.

Figure 5 indicates there is a decrease of the probability of failure for increasing values of the mean stone diameter, which is expected since larger diameters exhibit higher critical bed shear stresses, therefore, being less likely to be dragged away from the armour layer. This behaviour is in agreement with the results obtained by [11]. 
The deterministic design, previously presented, indicated that the methodology in [20] yielded more conservative sizes of the mean diameter. However, Figure 5, indicates that this methodology seems to be more conservative only for mean diameters larger than $0.42 \mathrm{~m}$ (vertical line in Figure 5). Conversely, as D50 decreases, the methodology in [20] yields smaller probabilities of failure than the methodology in [6]. Moreover, the methodology in [6] leads to a probability of failure of 1 for a mean diameter of $0.1 \mathrm{~m}$, while according to the methodology in [20] the probability is much smaller, roughly 0.03 . This difference points to a considerable uncertainty between both methodologies [6] and [20]. Such difference should be the aim of further research. Given these results, one may ask "are these two curves comparable?" i.e. can they be used to assess the same design situation? It is possible to argue that they are not since several different factors influence both criteria and may contribute for this somehow peculiar behaviour. Firstly, the results in Figure 5 considers an amplification factor of 2, which may not be the most reasonable choice for the waves and currents combined. As can be shown in Figure 6 , the probability of failure for the same mean stone diameter is highly dependent on the amplification factor, which is often determined by physical models adapted for a specific construction site.

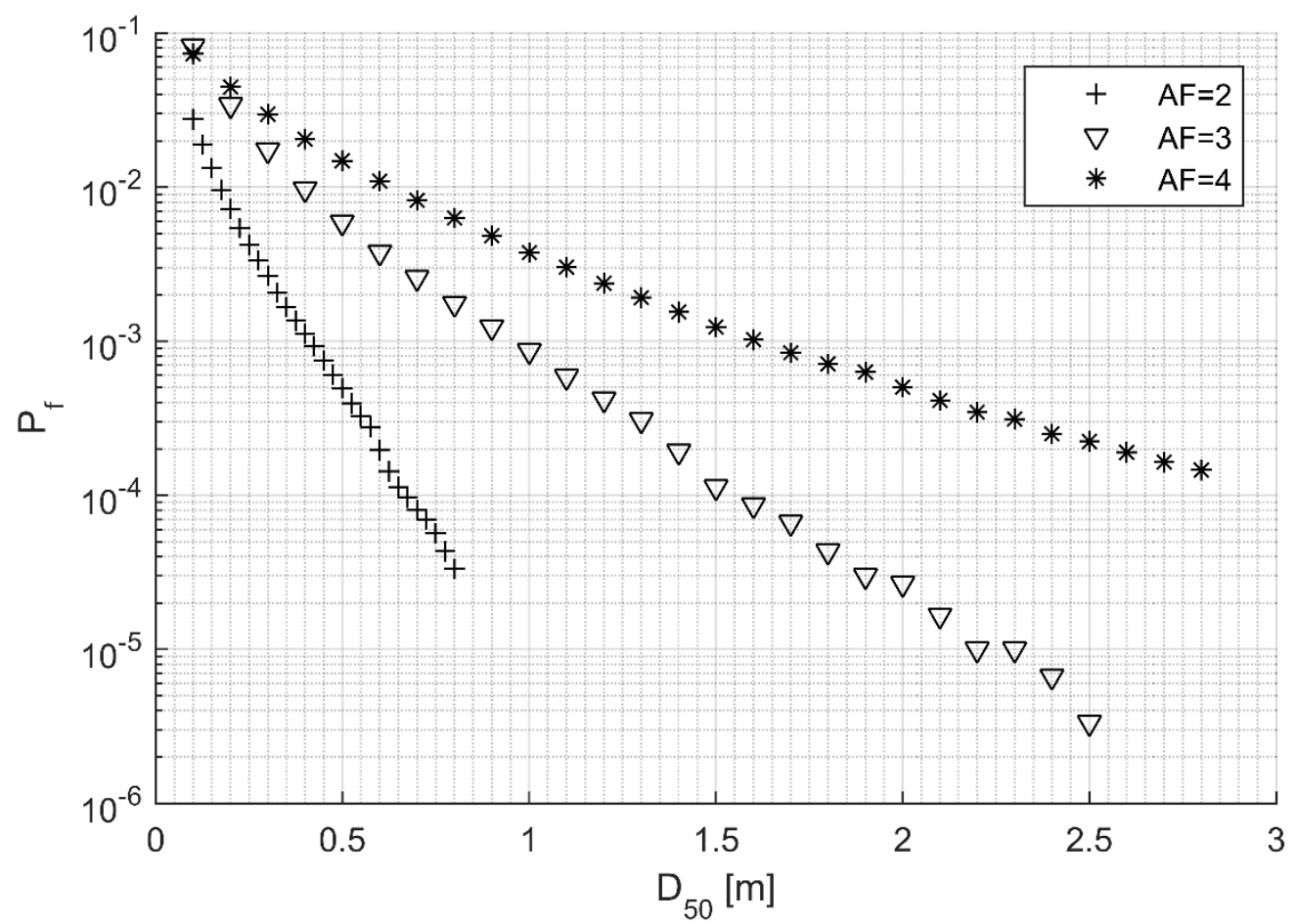

Figure 6. Influence of the amplification factor in the probability of failure for the methodology in [20] $(\mathrm{n}=300000)$. 
Figure 6 shows that when the amplification factor increases, a larger mean diameter must be chosen to obtain the same probability of failure. This emphasises the fact that the methodology proposed by [20] tends to be more conservative when the amplification factor is increased. Nevertheless, the authors note that the definition of the amplification factor may represent a drawback to the probabilistic design of static scour protections according to the methodology in [20]. Although, several authors use $\alpha=4$, this value can be larger or smaller, depending on the hydrodynamic conditions [18]. The fact that its evaluation is still assessed based on the empirical knowledge of the designer, makes it harder to define standard values of $\alpha$ that should be used to obtain the curve showed in Figure 5, which is intended to be comparable with the methodology in [6]. The effect of the amplification factor on the probability of failure increases for an increasing $\mathrm{D}_{50}$.

In agreement with the deterministic design previously performed, Figure 6 shows that amplification factors of 3 or 4 leads to very large mean stone diameters, which for a rip-rap scour protection may not be a feasible material to be placed with the fall-pipe vessels, as mentioned by [11].

Another aspect that may contribute to the behaviour showed in Figure 5 is the calculation of the critical bed shear stress. Figure 7 shows the critical bed shear stress as a function of the diameter of the stones. Note that, according to [6], the critical bed shear stress is calculated with $\theta_{\text {cr }}$ equal to 0.035 and using the diameter $\mathrm{D}_{67.5}$. On the other hand, the methodology in [20] uses $\theta_{\text {cr }}$ equal to 0.056 and the mean stone diameter $D_{50}$. One can think about the critical bed shear stress as being the resistance component of the limit state function (Eq.12). Figure 7 shows that, for smaller diameters, the difference between the resistance values obtained by both methodologies is less significant. This difference becomes more relevant as $\mathrm{D}_{50}$ increases. When the mean stone diameter increases, the resistance given by the methodology in [6] can be seen to increase less than the resistance obtained by the methodology in [20] (Figure 7). This should lead to larger probabilities given by the design according to [6] than according to in [20]. However, this effect may be opposed by the different calculation of the acting bed-shear stress which varies non-linearly with the increasing $\mathrm{D}_{50}$.

Moreover, the non-linearity of the combined wave- and current-induced bed shear stress with the variation of mean stone diameter may also contribute for the different behaviour between the curves shown in Figure 5. Further research should be carried to fully address the influence of this aspect. Note that the non-linear effects are mainly due to the influence of $\mathrm{D}_{50}$ on the wave and current friction factors, as shown by [49] and [50]. 


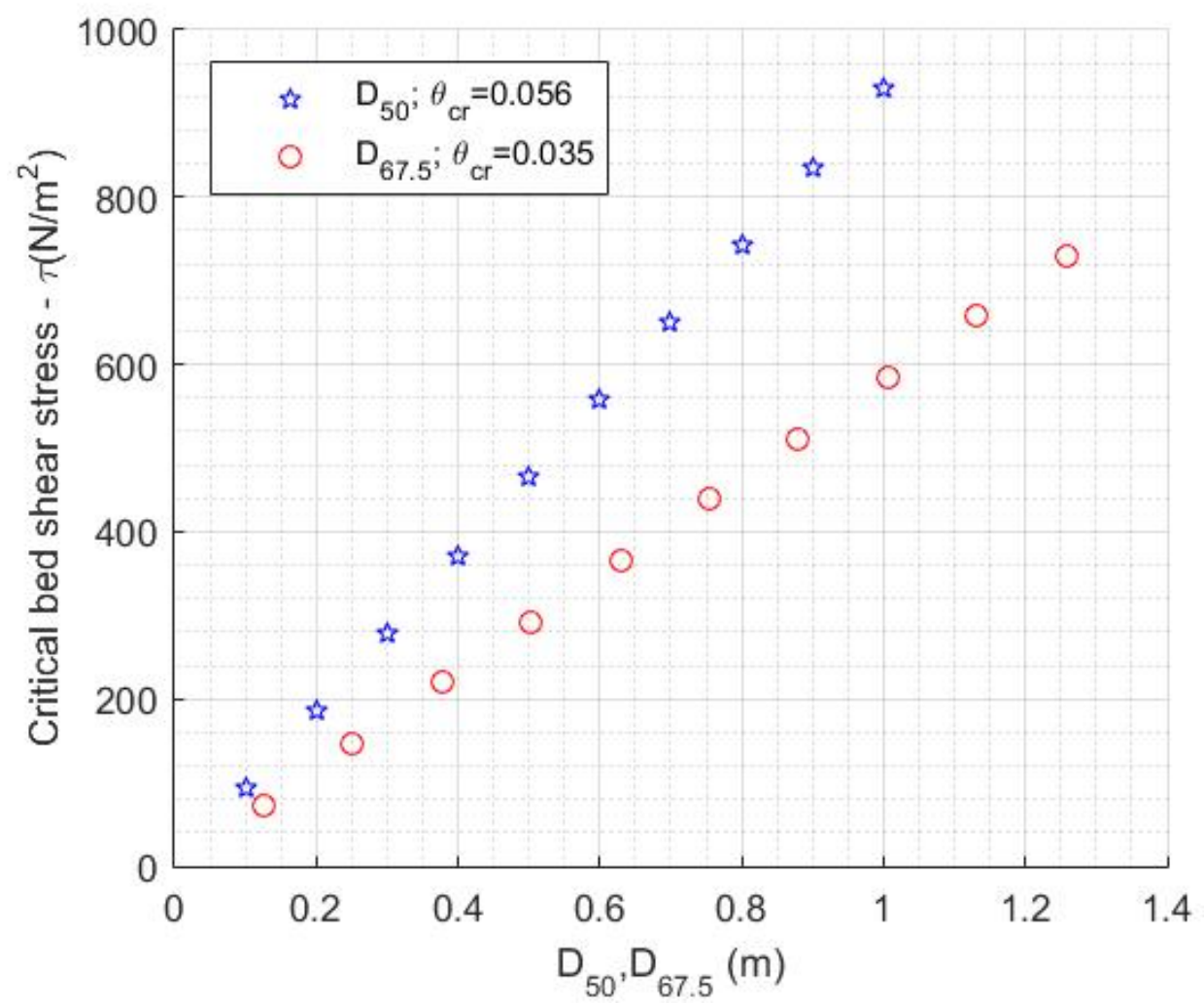

Figure 7. Comparison of the critical bed shear stress calculated by the methods in [6] and [20].

Finally, one must also note that the wave orbital bottom velocity $\left(U_{m}\right)$ is calculated for the significant wave height $\left(\mathrm{H}_{\mathrm{s}}\right)$ in the methodology in [20], while in the methodology in [6] it is calculated for the mean wave height of the top $10 \%$ of the waves $\left(\mathrm{H}_{1 / 10}\right)$. Therefore, the orbital bottom velocity used in [6] is more conservative than the one used in [20]. In non-cohesive sediments, as the ones studied in this case, research shows that the combined bed shear stress increases faster for smaller stone diameters, e.g. [3] and [6]. Therefore, when the diameter decreases, the effect caused by the different calculation of $U_{m}$ may also contribute to the larger values of the probability of failure showed by the methodology in [6]. When the mean diameter increases, the effects associated to $U_{m}$ dissipate and the methodology in [20] yields larger values of the probability of failure.

Figure 8 shows the probabilities of failure obtained with the methodology in [6] compared to those obtained with the methodology in [20] calculated with an amplification factor equal to 4 and $\mathrm{U}_{\mathrm{m}}$ calculated with $\mathrm{H}_{1 / 10}$. As expected, the probabilities of failure for the methodology in [20] increase considerably since $\mathrm{U}_{\mathrm{m}}\left(\mathrm{H}_{\mathrm{s}}\right)<\mathrm{U}_{\mathrm{m}}\left(\mathrm{H}_{1 / 10}\right)$. For the sake of comparison, Figure 8 is limited to $\mathrm{D}_{50}=0.9 \mathrm{~m}$, because the methodology in [20] only yields smaller probabilities of 
failure for very large diameters (see Figure 6). In the case of Figure 8, it is possible to see that the intersection point between both methodologies occurs sooner than showed in Figure 5, close to $\mathrm{D}_{50}=0.16 \mathrm{~m}$.

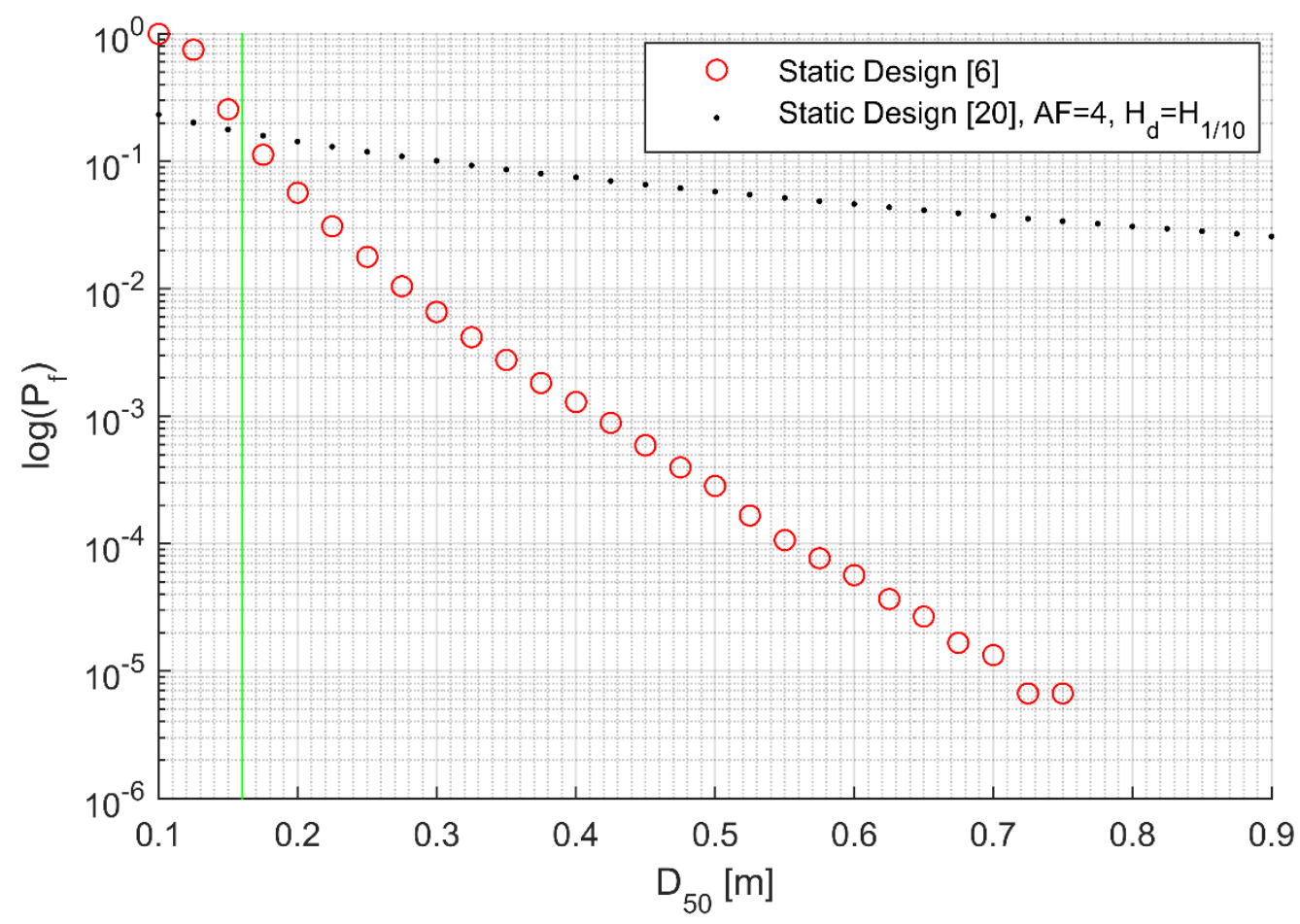

Figure 8. Influence of $U_{m}$ in the probability of failure for the methodology in [20], compared with the standard application of the methodology in [6] $(n=300000)$.

These results show that, for static scour protections, it might be difficult to select a $\mathrm{D}_{50}$ for a pre-defined probability of failure. Nevertheless, in the present case study, for probabilities of failure smaller than $10^{-3}$, the methodology in [6] consistently leads to smaller mean stone diameters (see Figure 5 and Figure 6). In practical situations, it is recommended that both curves are established and analysed before selecting the design value of $\mathrm{D}_{50}$. Moreover, it is also noted that selecting $\mathrm{D}_{50}$ may also depend on factors such as the available material, the transportation cost and the construction technique (e.g. fall-pipe vessels, cranes, lifters), which may lead the designer into avoiding the use of very large diameters, e.g. above $0.8 \mathrm{~m}$.

When designing a dynamic scour protection, it is important to establish the relation between the stone diameter and the probability of failure for the criterion presented in [14]. Moreover, since the methodology presented in [14] is an improvement of the method for static scour protections proposed in [6], it is also important to understand if both criteria provide an equivalent safety 
level, i.e. is there a relation between a static scour protection designed with a certain $\mathrm{D}_{50}$ and a dynamic scour protection designed with a reduced $\mathrm{D}_{50} *$, for any $\mathrm{D}_{50}{ }^{*}<\mathrm{D}_{50}$.

Figure 9 presents the comparison of both methodologies for the case study introduced in the previous section. For the tested range of mean stone diameters, it can be seen that the criterion proposed by the static design consistently leads to larger probabilities of failure for the same mean stone diameter. This is expected since the dynamic design allows for the movement of the stones, which means that smaller diameters can be used in the design without considering that failure occurs. However, a fair comparison between criteria must be performed for different diameters, i.e. the one used for a static design and the reduced one used in the dynamic design. Point A $\left(0.26 \mathrm{~m} ; 5 \times 10^{-4}\right)$ and Point B $\left(0.54 \mathrm{~m} ; 1.7 \times 10^{-4}\right)$ in Figure 9 correspond to the deterministic design values previously presented for the dynamic and static scour protections, respectively. As seen before, these two points show that the probability of failure is larger for the reduced diameter $D_{50} *$. However, one is able to see that other values of $D_{50}$ could be used, smaller than $\mathrm{D}_{50}=0.54 \mathrm{~m}$ but larger than $0.26 \mathrm{~m}$, still yielding probabilities of failure which are are in the order of $10^{-4}$. For example, if the designer is not comfortable with using a $\mathrm{D}_{50} *=0.26$ $\mathrm{m}$, he may still use, for instance, a $\mathrm{D}_{50}=0.45 \mathrm{~m}$, which yields a value of $\mathrm{P}_{\mathrm{f}}$ in the order of $10^{-5}$ for the dynamic criteria and $10^{-4}$ in the static one, but still represents a smaller mean diameter when compared with the one required for static stability, i.e. $\mathrm{D}_{50}=0.54 \mathrm{~m}$. In this sense, and for design purposes, one is now able to select the mean stone diameter for a pre-defined probability of failure from the curves showed in Figure 9.

Figure 9 shows that, depending on the level of safety, i.e. for the same probability of failure, the "static mean stone diameter" can be approximately reduced by 10 to $15 \mathrm{~cm}$ if one uses a "dynamic mean stone diameter". This is of great importance as, for the present case study, it helps to validate that a solution based on a dynamic scour protection yields a similar level of reliability as the one based on the static design. Furthermore, it enables the designer to understand how the proposed reduction in the diameter is influencing the safety level according to the statically stable or dynamically stable criteria. Eventually, the designer may adopt an intermediate solution between both diameters and he is still optimising the dimension of the protection when compared with the traditional static design.

As seen when dealing with the reliability assessment of the deterministic design approach, the authors note that further research should be performed in order to generalize this procedure for other case studies. The lack of research addressing the probabilistic design of scour protections for offshore wind turbines leaves space to improve these results and to compare them with 
different design conditions. However, the confidential policies concerning data sharing, design procedures and the occurrence of failures in the offshore wind industry do not facilitate the increase in the number of case studies to be analysed. Therefore, only a confined group of people has experience and knowledge to design scour protections [6]. Nevertheless, the successful development of physical model studies concerning dynamic scour protections, e.g. [12], [13], [14] and [15], as well as the consistent levels of safety that were identified for the present case study justify the need for further research on the matter as a possible way to optimise the design of scour protections.

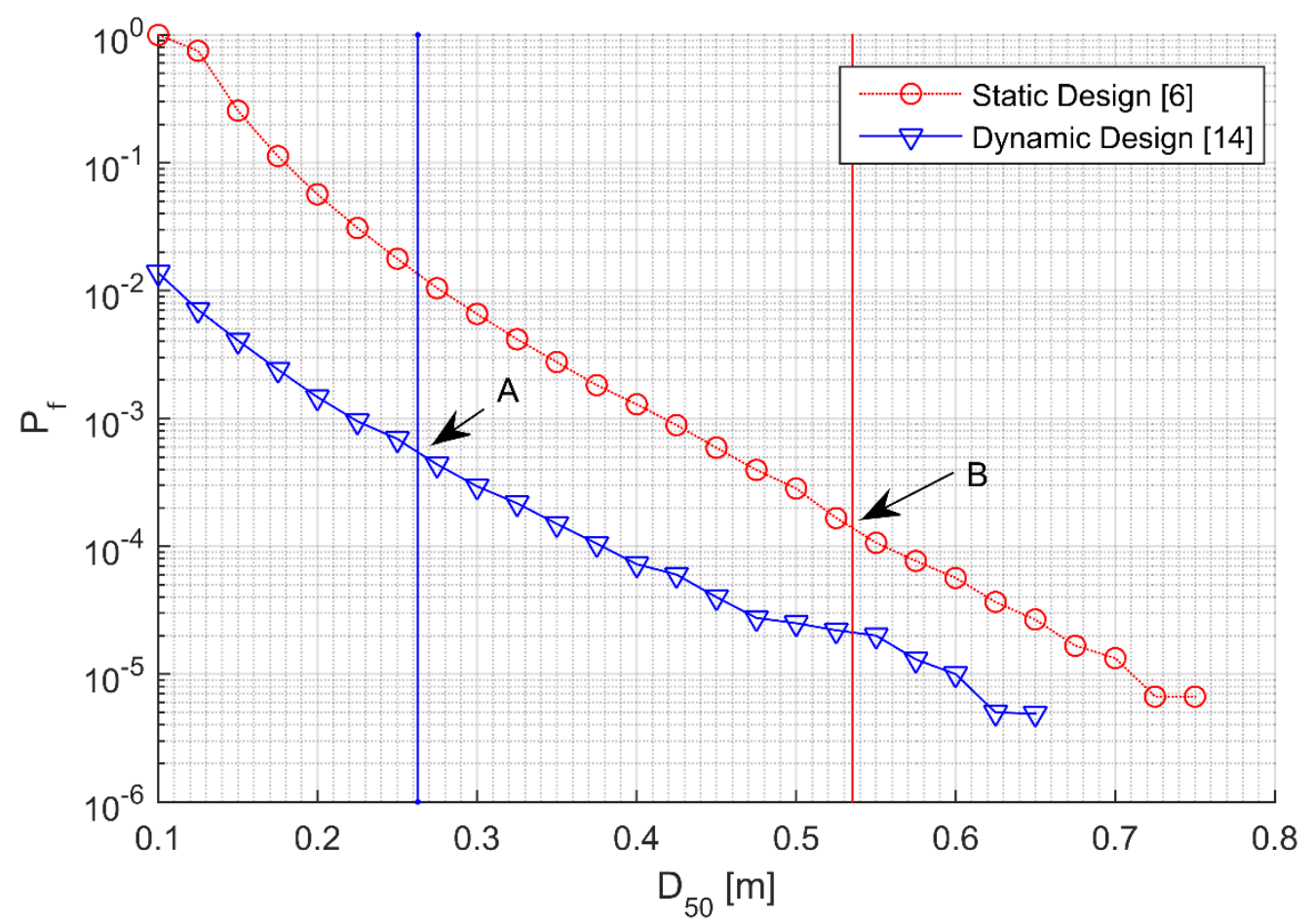

Figure 9. Probabilities of failure as a function of the mean stone diameter, comparison between static [6] and dynamic design [20].

\section{CONCLUSIONS}

A methodology to perform the reliability assessment and the probabilistic design of static and dynamic scour protections was performed by means of a case study. The research was based on the met-ocean data available for Horns Rev 3 offshore windfarm. For the considered case study, it was concluded that it is possible to design a dynamic scour protection, according to [14], with a similar reliability of a static scour protection designed according to [6]. Moreover, both design methodologies showed that the reduction of the mean diameter, from a static 
stability towards a dynamic stability, may be used for practical purposes. One is able to use a mean diameter between the statically stable and the dynamically stable one within the same order of the probability of exceeding the design criterion.

It was also concluded that further research should be carried in order to properly address the comparison between the probabilistic design made with the methodology [6] and [20]. It was found that the probability of failure was considerably influenced by the amplification factor, the Shields critical parameter, the diameter used to compute the critical bed shear-stress and the calculation of the orbital bottom velocity. The design options made regarding these aspects may invalidate a straight comparison between the criteria adopted by [6] and [20]. Nevertheless, for probabilities smaller than $10^{-3}$, regardless of the amplification factor the methodology [20] tended to provide larger mean diameters than the methodology [6]. However, it is advisable to perform the reliability assessment for several values of the amplification factor, so that the design decisions are better informed. Also the proposed design should always be validated by means of physical model studies, as it is common in scour protection studies, e.g. [11] and [15]. The findings of this paper suggest that in practical situations one should calculate the relationship between the mean stone diameter and the probability of failure for several methodologies, in order to make an informed design decision. Moreover, the analysis of the influence of the time resolution of the records of $\mathrm{H}_{\mathrm{s}}$ and $\mathrm{T}_{\mathrm{p}}$ on the probabilities obtained remains to be fully understood. Further research should address this aspect, since typical guidelines for structural design are referred to annual values. The influence of the statistical model used to generate correlated wave heights and periods, as well as the correlation between the sea-state and the current velocity, are also key aspects to improve the accuracy of reliability analysis applied to scour protections. Finally, it should also be noted that the reliability analysis based on different design criteria and the possible probabilistic design require a clear definition on the general rules that define the required protection's safety level, which are yet not found in the literature and should be the aim of future research.

\section{ACKNOWLEDGEMENTS}

T. Fazeres-Ferradosa is funded by the Portuguese Foundation for Science and Technology (FCT) under the Ph.D. scholarship PB/BD/113454/2015 - Doctoral Program INFRARISK. T. Fazeres-Ferradosa acknowledges Dr. Francisco Q. Fazeres (ULSAM) on the enlightening discussions on survival and reliability analysis. 
[1] WindEurope, “The European Offshore Wind Industry: key trends and statistics 2016," WindEurope, Brussels, 2017.

[2] L. Prendergast, K. Gavin and P. Doherty, "An investigation into the effect of scour on the natural frequency of an offshore wind turbine," Ocean Engineering. vol. 101 (1), pp. 1-11, 2015.

[3] L. De Vos, "Optimisation of Scour Protection Design for Monopiles and Quantification of Wave Run-Up Engineering the Influence of an Offshore Wind Turbine on Local Flow Conditions - PhD Thesis," University of Ghent, Ghent, 2008.

[4] M. B. Zaaijer and J. Tempel, "Scour Protection: A Necessity or a Waste of Money?," in Proceedings of the 43th IEA Topixal Expert Meeting, Stockholm, 2004.

[5] R. Whitehouse, Scour at marine structures: A manual for practical applications, London: Institution of Civil Engineers, 1998.

[6] L. De Vos, J. d. Rouck, P. Troch and P. Frigaard, "Empirical design of scour protections around monopile foundations. Part 1: Static approach," Coastal Engineering, vol. 58, pp. 540-553, 2011.

[7] C. Matutano, V. Negro, J.-S. López-Gutiérrez and M. D. Esteban, "Scour prediction and scour protections in offshore wind farms," Renewable Energy, vol. 57, pp. 358-365, 2013.

[8] S. Bhattacharya, "Challenges in Design of Foundations for Offshore Wind Turbines," Engineering and Technology Reference, pp. 1-9, 2014.

[9] A. Gonzalez-Rodriguez, "Review of offshore wind farm cost components," Energy for Sustainable Development, pp. 10-19, 2017.

[10] J. H. den Boon, J. Sutherland, R. Whitehouse, R. Soulsby, C. J. M. Stam, K. Verhoeven, M. Høgedal and T. Hald, "Scour behaviour and scour protection for monopile foundations of offshore wind turbines," in European Wind Energy Conference \& Exhibition, London, UK, 2004.

[11] T. Fazeres-Ferradosa, F. Taveira-Pinto, L. d. Neves and M. T. Reis, "Design of Scour Protections and Structural Reliability Techniques," in Sustainable Hydraulics in the Era of Global Change, Chapter 85, Liege, CRC Press, Print ISBN 978-1-138-02977-4, DOI: 10.1201/b21902-91, 2016, p. 527-532.

[12] P. Schoesitter, S. Audenart, L. Baelus, A. Bolle, A. Brown, L. d. Neves, T. Fazeres-Ferradosa, P. Harens, F. Taveira-Pinto, P. Troch and R. Whitehouse, "Feasibility of a dynamically stable rock armour layer scour protection for offshore wind farms," in International Conference on Ocean, Offshore and Artic Engineering, San Francisco, California, 2014.

[13] E-Connection, Vestas Wind Systems D.K. Germanischer Lloyd Windenergie D, "OPTI-PILE, Fifth Research and Technological Development Framework.," 2002-2004.

[14] L. De Vos, J. De Rouck, P. Troch and P. Frigaard, "Empirical design of scour protections around monopile foundations - Part 2 - Dynamic approach,” Coastal Engineering, vol. 60, pp. 286-298, 2012.

[15] R. Whitehouse, A. Brown, S. Audenaert, A. Bolle, P. Schoesitter, P. Haerens, L. Baelus, P. Troch, L. d. Neves, T. Fazeres-Ferradosa and F. Taveira-Pinto, "Optimising scour protection stability at offshore foundations," in Proceedings of the 7th International Conference on Scour and Erosion, Pearth, Australia, 2014.

[16] J. Fredsøe and R. Deigaard, Mechanics of Coastal Sediment Transport - Advanced Series on Ocean Engineering, vol 3, Singapure: World Scientific, 1992.

[17] B. Melville and S. Coleman, Bridge Scour, USA - Colorado: Water Resources Publications, 2000.

[18] B. M. Sumer and J. Fredsøe, The Mechanics of Scour in the Marine Environment, Singapure: World Scientific, 2002.

[19] A. Agrawal, M. Khan and Z. Yi, "Handbook of Countermeasures Designs - report No FHWA-NJ-2005-027," New Jersey Department of Transportation \& Federal Highway Administration US Department of Tranportation Washington D.C., 2007.

[20] R. Soulsby, Dynamics of marine sands: a manual for practical applications, Thomas Telford, 1997.

[21] A. F. Shields, "Application of similarity principles and turbulence research to bed-load movement, vol 26," Mitteilungen der Preussischen Versuchsanstalt f€ur Wasserbau und Schiffbau, pp. 5-24, 1936.

[22] R. Soulsby and S. Clarke, "Bed Shear-Stresses Under Combined Waves and Currents on Smooth and Rough Beds. Report TR 137,” HR Wallingford, UK, 2005.

[23] J. Malarkey and A. Davies, “A simple procedure for calculating the mean and maximum bed stress under 
wave and current conditions for rough turbulent flow based on Soulsby and Clarke's (2005) method," Computers \& Geosciences, vol. 43, pp. 101-107, 2011.

[24] A. Schendel, N. Goseberg and T. Schlurmann, "Experimental study on the performance of coarse grain materials as scour protection," in Coastal Engineering Proceedings - 34th International Conference on Costal Engineering, Seul, 2014.

[25] K. Bruserud, S. Haver and D. Myrhaug, "Joint description of waves and currents applied in a simplified load case," Marine Structures, vol. 58, pp. 416-433, 2018.

[26] K. Bruserud and S. Haver, "Waves and associated currents-experiences from 5 years metocean measurements in the northern North Sea," Marine Structures, vol. 2, p. In Press, 2017.

[27] T. Fazeres-Ferradosa and F. Taveira-Pinto, "Pre-assessing the feasibility of a design performance function for scour protection systems in offshore foundations," in Conference Proceedings of the 36th IAHR World Congress, The Hague, 2015.

[28] E. Vanem, "Uncertainties in extreme value modelling of wave data in a climate change," Journal of Ocean Engineering and Marine Energy, pp. 339-359, 2015.

[29] F. Fajardo, J. Perez, M. Alsina and J. R.-. Marques, Simulation Methods for Reliability and Availability of Complex Systems, New York: Springer, 2010.

[30] DMI, "Horns Rev 3 Offshore Wind Farm - Metaocean,” DMI - Danish Metereological Institute \& Orbicon A/S, Copenhagen, Denmark, 2013.

[31] Energinet, "Horns Rev 3 Offshore Wind Farm - marine mammals - technical report 043," Energinet, Orbicon A/S, BioConsult SH GmbH \& Co.KG, Denmark, 2014.

[32] H. Kristensen, H. L. B. Gurieff, J. Steer and N. Richard, "Horns Rev 3 Results Report - Geo investigation 2012," Rambøll og Energinet, 2013.

[33] S. Rodrigues, C. Restrepob, E. Kontos, R. T. Pinto and P. Bauer, "Trends of offshore wind projects," Renewable and Sustainable Energy Reviews, vol. 49, p. 1114-1135, 2015.

[34] DNVGL, "DNV Recommended Practice C205 - Environmental Loads and Conditions," Det Norsk Veritas AS, Norway, 2017.

[35] E. Bitner-Gregersen, "Joint met-ocean description for design and operation of marine structures," Applied Ocean Research, pp. 279-292, 2015.

[36] E. M. Bitner-Gregersen and S. Haver, "Joint Environmental Model for Reliability Calculations," in Proceedings of the 1st International Offshore and Polar Engineering Conference, Edinburgh, United Kingdom, 1991.

[37] E. Vanem, "Joint statistical models for significant wave height and wave period in a changing climate," Marine Structures, vol. 49, pp. 180-205, 2016.

[38] C. Lucas and C. Guedes-Soares, "Bivariate distributions of significant wave height and mean wave period of combined sea states," Ocean Engineering, vol. 106, pp. 341-353, 2015.

[39] P. Jonathan and K. Ewans, "Statistical Modelling of extreme ocean environments for marine design: A review," vol. 62, pp. 91-109, 2013.

[40] Vattenfall, "corporate.vattenfall.dk," 2017. [Online]. Available: https://corporate.vattenfall.dk/globalassets/danmark/vores_vindmoller/horns_rev_3/hr3_nyhedsbrev_01.pdf. [Accessed 11012018$].$

[41] R. Whitehouse, J. Harris, J. Sutherland and J. Rees, "The nature of scour development and scour protection at offshore windfarm foundations," Marine Pollution Bulletin. Volume 62. Issue 1, pp. 73-88, 2011.

[42] G. Hoffmans and H. Verheij, Scour Manual, Rotterdam: CRC Press, 1997.

[43] A.C.Z., Van Oord, "Scour Protection for 6 MW OWEC with Monopile Foundation in North Sea," Gorinchem, 2003.

[44] T. Petersen, B. Sumer, J. Fredsøe and J. Schouten, "Edge scour at scour protections around piles in marine environment - Laboratory and field investigation," Coastal Engineering, vol. 106, pp. 42-72, 2015.

[45] R. Montes-Iturrizaga and E. Heredia-Zavoni, "Reliability analysis of mooring lines using copulas to model statistical dependence of environmental variables," Applied Ocean Research. vol. 59., pp. 564-576, 2016.

[46] DNV, "Classification Notes. N30.6 - Structural Reliability Analysis of Marine Structures," Det Norske Veritas, 1992.

[47] DNVGL, "DNVGL - ST- 0262 - Lifetime extension of wind turbines," Det Norske Veritas AS, Norway, 2017. 
[48] S. Winterstein, G. Kleiven and O. Hagen, "Comparing extreme wave estimates from hourly and annual data," in Proceedings of the International Offshore and Polar Engineering Conference, Stavanger, Norway, 2001.

[49] R. Simons, T. J. Grass, W. Saleh and M. M. Tehrani, "Bottom shear stresses under waves with a current superimposed," in 24th International Conference on Coastal Engineering, Kobe, Japan, 1994.

[50] A. Roulund, J. Sutherland, D. Todd and J. Sterner, "Parametric equations for Shields parameter and wave orbital velocity in combined current and irregular waves," in Proceedings of the 8th International Conference on Scour and Erosion, Oxford, UK, 2016. 